This item was submitted to Loughborough's Research Repository by the author.

Items in Figshare are protected by copyright, with all rights reserved, unless otherwise indicated.

\title{
Oral nitrate reduction is not impaired after training in chlorinated swimming pool water in elite swimmers
}

PLEASE CITE THE PUBLISHED VERSION

https://doi.org/10.1139/apnm-2020-0357

PUBLISHER

NRC Research Press (Canadian Science Publishing)

VERSION

AM (Accepted Manuscript)

PUBLISHER STATEMENT

This paper was accepted for publication in the journal Applied Physiology, Nutrition, and Metabolism and the definitive published version is available at https://doi.org/10.1139/apnm-2020-0357.

\section{LICENCE}

CC BY-NC-ND 4.0

\section{REPOSITORY RECORD}

Rowland, Samantha, Richard Chessor, George French, George Robinson, Emma ODonnell, Lewis James, and Stephen Bailey. 2020. "Oral Nitrate Reduction Is Not Impaired After Training in Chlorinated Swimming Pool Water in Elite Swimmers”. Loughborough University. https://hdl.handle.net/2134/12815984.v1. 


\section{Applied Physiology, Nutrition, and Metal}

\section{Oral nitrate reduction is not impaired after training in chlorinated swimming pool water in elite swimmers}

\begin{tabular}{|c|c|}
\hline Journal: & Applied Physiology, Nutrition, and Metabolism \\
\hline Manuscript ID & apnm-2020-0357.R1 \\
\hline Manuscript Type: & Brief communication \\
\hline $\begin{array}{r}\text { Date Submitted by the } \\
\text { Author: }\end{array}$ & $n / a$ \\
\hline Complete List of Authors: & $\begin{array}{l}\text { Rowland, Samantha ; Loughborough University, School of Sport, } \\
\text { Exercise and Health Sciences } \\
\text { Chessor, Richard; British Swimming } \\
\text { French, George; Loughborough University, School of Sport, Exercise and } \\
\text { Health Sciences } \\
\text { Robinson, Geroge; Loughborough University, School of Sport, Exercise } \\
\text { and Health Sciences } \\
\text { O'Donnell, Emma; Loughborough University, SSEHS } \\
\text { James, Lewis; Loughborough University, School of Sport, Exercise and } \\
\text { Health Sciences } \\
\text { Bailey, Stephen; Loughborough University, School of Sport, Exercise and } \\
\text { Health Sciences; }\end{array}$ \\
\hline $\begin{array}{r}\text { Novelty bullets: points that } \\
\text { summarize the key findings in } \\
\text { the work: }\end{array}$ & $\begin{array}{l}\text { Oral nitrate reduction is similar in elite swimmers and non-swimming } \\
\text { controls., Oral nitrate reduction is similar pre and post training in } \\
\text { chlorinated water in elite swimmers. }\end{array}$ \\
\hline Keyword: & $\begin{array}{l}\text { Nitrate, nitrite, oral nitrate-reducing capacity, swimming }<\text { sports, } \\
\text { chlorine, elite athletes }<\text { athletes }\end{array}$ \\
\hline $\begin{array}{l}\text { Is the invited manuscript for } \\
\text { consideration in a Special } \\
\text { Issue? : }\end{array}$ & Not applicable (regular submission) \\
\hline
\end{tabular}

\section{SCHOLARONE Manuscripts}


$1 \quad$ Oral nitrate reduction is not impaired after training in chlorinated swimming pool water in elite swimmers

3 Samantha N. Rowland ${ }^{1}$, Richard Chessor ${ }^{2}$, George French ${ }^{1}$, George P. Robinson ${ }^{1}$, 4 Emma O'Donnell ${ }^{1}$, Lewis J James ${ }^{1}$, Stephen J. Bailey ${ }^{1}$

5 1. School of Sport, Exercise and Health Sciences, Loughborough University, United $6 \quad$ Kingdom.

7 2. British Swimming, Loughborough University, United Kingdom.

8 Emails: $\quad$ S.Rowland@lboro.ac.uk; richard.chessor@swimming.org;

9 georgewfrench96@gmail.com; G.Robinson@lboro.ac.uk; E.ODonnell@lboro.ac.uk;

10 L.James@lboro.ac.uk; S.Bailey2@lboro.ac.uk.

12 Address for correspondence:

13 Stephen J Bailey

14 School of Sport, Exercise and Health Sciences

15 Loughborough University

16 Loughborough

17 United Kingdom

18 LE11 3TU

19 Tel: +44 (0)1509226433

20 


\section{Abstract}

36 This study tested the hypothesis that exposure to chlorine-sterilised pool water would

37 impair oral nitrate reduction (ONR). ONR was assessed in elite swimmers before and after morning and afternoon pool-based training. Non-swimmers were only assessed in the morning. ONR was similar in swimmers and non-swimmers $(P=1.000)$ and unchanged pre to post morning and afternoon training $(P \geq 0.341)$. Therefore, exposure to chlorinated pool water does not interfere with ONR.

42

Key words: Nitrate, nitrite, oral nitrate-reducing capacity, swimming, chlorine

44

45

46

47

48

49

50

51

52

53

54

55

56

57

58

59

60

61

62

63

64

65

66 


\section{Introduction}

Dietary nitrate $\left(\mathrm{NO}_{3}{ }^{-}\right)$supplementation has been shown to improve exercise performance in a variety of settings, with its ergogenic effect believed to be linked to the stepwise reduction of $\mathrm{NO}_{3}{ }^{-}$to nitrite $\left(\mathrm{NO}_{2}{ }^{-}\right)$and $\mathrm{NO}_{2}{ }^{-}$to nitric oxide (NO) (Jones et al. 2018). The increase in salivary and plasma $\left[\mathrm{NO}_{2}{ }^{-}\right]$after $\mathrm{NO}_{3}{ }^{-}$ingestion is critically dependent on oral $\mathrm{NO}_{3}{ }^{-}$reduction (ONR) catalysed by anaerobic bacteria residing in the oral cavity (Govoni et al. 2008). Indeed, numerous studies have demonstrated that removal of these bacteria with antibacterial mouthwash markedly blunts the increases in salivary and plasma $\left[\mathrm{NO}_{2}{ }^{-}\right]$, and the associated NO-mediated biological effects, following inorganic $\mathrm{NO}_{3}^{-}$supplementation (Senkus and Crowe-White 2019). Moreover, it appears that the magnitude by which antibacterial mouthwashes blunt ONR and associated physiological responses after $\mathrm{NO}_{3}{ }^{-}$supplementation is a function of their antibacterial potency (Woessner et al. 2016).

Chlorine confers potent antibacterial properties and is commonly used to disinfect swimming pool water. Accordingly, exposure to chlorine-sterilised pool water has the potential to impede $\mathrm{NO}_{3}{ }^{-}$reducing oral microflora, and subsequently, the physiological and ergogenic benefits that attend $\mathrm{NO}_{3}{ }^{-}$supplementation. Recent publications have not observed an ergogenic effect of $\mathrm{NO}_{3}{ }^{-}$supplementation in trained swimmers (Lowings et al. 2017; Jonvik et al. 2018; Esen et al. 2019). Whilst this lack of an ergogenic effect following $\mathrm{NO}_{3}{ }^{-}$supplementation could be a function of chlorinemediated impairments in ONR, it has yet to be determined whether exposure to chlorine-sterilised pool water interferes with ONR. Therefore, the purpose of this study was to test the hypotheses that ONR would be: 1) lower in elite swimmers compared to non-swimmers; 2) lower after, compared to before, a pool-based training session in elite swimmers in the morning and afternoon, and lower following the afternoon compared to the morning session on the same day; and 3) negatively correlated with the pool-based training session duration.

\section{Methods}

\section{Participants}

Thirteen full-time elite swimmers ( 8 males, mean \pm SD: age: $21 \pm 2$ years, height: 1.83 $\pm 0.09 \mathrm{~m}$, body mass: $75.1 \pm 10.4 \mathrm{~kg}$ ) and fourteen non-swimmer controls (9 males, $25 \pm 4$ years, $1.77 \pm 0.10 \mathrm{~m}, 70.1 \pm 12.1 \mathrm{~kg}$ ) volunteered to participate in this study. 
The swimmers trained at Loughborough National Centre which is part of the British Swimming World Class Programme. On average the swimmers had 4.4 years of experience in national level swimming and above during the year of data collection. The swimmers completed between 10-13 exercise sessions per week (including up to 10 pool and 3 land sessions). The control participants were recreationally active and infrequent swimmers (using swimming pools less than once per month). Ethical approval for this study was granted by Loughborough University's Ethics Advisory Committee. All participants provided written informed consent prior to participation in the study. Participants were given a list of nitrate-rich foods to avoid consuming $24 \mathrm{~h}$ before testing sessions and were asked to consume the same foods and drinks the evening prior to experimental visits. They were also told to avoid caffeine and alcohol ingestion $12 \mathrm{~h}$ and $24 \mathrm{~h}$ before trials, respectively. For the duration of the study, participants were instructed to abstain from using antibacterial mouthwash (Govoni et al. 2008) and to avoid brushing their teeth and tongue on the day of trials (Tribble et al. 2019).

\section{Experimental design}

The elite swimmers completed 3 visits in total. During the first visit, swimmers were familiarised with the procedures involved in this study. In successive visits, as part of a randomised, double-blind crossover experimental design, ONR was assessed pre and post both a morning ( $7.30 \mathrm{am}$; AM-Pre and AM-Post, respectively) and afternoon ( 3.30 pm; PM-Pre and PM-Post, respectively) in-water training session in one of the two experimental conditions [nitrate-rich $(\mathrm{NR})$ or nitrate-depleted $(\mathrm{PL})$ mouth rinse]. Mouth rinse solutions were given on arrival at the pool before training and within 5 minutes of swimmers exiting the water after their session. The morning and afternoon sessions ( $91 \pm 26 \mathrm{~min}$ and $103 \pm 19 \mathrm{~min}$, respectively) were separated by $\sim 6 \mathrm{~h}$. This was then repeated 2-14 days later with the alternative experimental treatment. Chlorine concentration $(1.39 \pm 0.10 \mathrm{mg} / \mathrm{L})$ was adequately maintained within recommended guidelines of $1-3 \mathrm{mg} / \mathrm{L}$ throughout (WHO 2006). Non-swimmers attended the laboratory in the morning on one occasion for the assessment of ONR.

\section{Measurements}

Oral nitrate-reducing capacity 
134 The mouth rinse solutions were prepared the day before administration and stored at $4^{\circ} \mathrm{C}$. Prior to administration, all solutions were placed in a heated water bath at $36^{\circ} \mathrm{C}$ to match oral temperature (Sund-Levander et al. 2002). Participants were then asked to hold $10 \mathrm{~mL}$ of water (Buxton Mineral Water, UK) in their oral cavity for 3 min before expectorating into a $50 \mathrm{~mL}$ Falcon tube. Following $3 \mathrm{~min}$ rest, participants held either $10 \mathrm{~mL}$ of $1 \mathrm{mM} \mathrm{KNO}_{3}$ solution (NR: Minerals-Water.Itd, Purfleet, UK) or a solution with a negligible $\mathrm{NO}_{3}{ }^{-}$content (PL: Buxton Mineral Water alone) for 3 min before expectorating into a $50 \mathrm{~mL}$ Falcon tube. This protocol is similar to a previous protocol used to assess ONR (Doel et al. 2005). The expectorated samples were then frozen at $-80^{\circ} \mathrm{C}$ for later analysis of ONR capacity through assessment of $\mathrm{NO}_{2}{ }^{-}$production, having accounted for baseline oral $\left[\mathrm{NO}_{2}^{-}\right]$in the initial water mouth rinse.

\section{Salivary $\left[\mathrm{NO}_{2}^{-}\right]$determination}

147 After thawing at room temperature, samples were centrifuged for $10 \mathrm{~min}$ at 14,000 rpm and the supernatant was removed and diluted 100-fold with deionised water for subsequent analysis. The $\left[\mathrm{NO}_{2}^{-}\right]$of the saliva samples was determined by its reduction to $\mathrm{NO}$ in the presence of glacial acetic acid and aqueous sodium iodide $(4 \% \mathrm{w} / \mathrm{v})$ via $50 \mu \mathrm{L}$ injections into the septum of the air-tight purge vessel using a gas-phase chemiluminescence NO analyser (Sievers NOA 280i, Analytix Ltd, Durham, UK).

\section{Statistical analysis}

Statistical analysis was performed using IBM SPSS Statistics version 25. Shapiro Wilk's test was used to check data normality and, when violated, a non-parametric test was used. The Mann-Whitney $U$ test was used to assess differences in ONR between swimmers and non-swimmers with effect size (ES) calculated as $Z / \sqrt{ } \mathrm{n}$. A two way (supplement $\times$ time) repeated-measures ANOVA was used to assess ONR in the swimmers with ES calculated using partial eta squared $\left(n_{p}^{2}\right)$. Where the ANOVA revealed a significant effect, paired $t$-tests with LSD correction were utilised to determine the origin of any effects with ES calculated as Cohen's $d_{z}(t / \sqrt{ } n)$. Pearson's product moment correlation coefficient was used to determine the relationship between swimming session duration and ONR. All parametric data are presented as mean \pm SD and all non-parametric data are presented as median and inter-quartile range $\left(25^{\text {th }}\right.$ and $75^{\text {th }}$ percentiles) unless otherwise stated. Statistical significance was accepted at $P<0.05$. 


\section{$\underline{\text { Results }}$}

There was no difference in ONR between swimmers $99(41,143) \mathrm{nmol} \cdot \mathrm{min}^{-1}$ and nonswimmers $56(42,165) \mathrm{nmol} \cdot \mathrm{min}^{-1}(P=1.000$; ES $=0.01$; Figure 1$)$. There was a main effect for supplement $(P<0.001$; ES $=0.71)$ and a supplement $\times$ time interaction effect for ONR in swimmers $(P=0.028$; ES $=0.22$; Figure 1$)$. The mean ONR across the AM-Pre, AM-Post, PM-Pre and PM-Post time points in the PL mouth rinse condition was $6 \pm 25 \mathrm{nmol} \cdot \mathrm{min}^{-1}$. ONR was higher at the AM-Pre, AM-Post, PM-Pre and PMPost time points with the NR solution compared to all time points with the PL mouth rinse condition (all $P \leq 0.002)$. ONR in NR was not different between AM-Pre $(98 \pm 67$ $\left.\mathrm{nmol} \cdot \mathrm{min}^{-1}\right)$ and AM-Post $\left(124 \pm 110 \mathrm{nmol} \cdot \mathrm{min}^{-1} ; \mathrm{ES}=0.28 ; P=0.341\right)$, or PM-Pre $\left(156 \pm 99 \mathrm{nmol} \cdot \mathrm{min}^{-1}\right)$ and PM-Post $\left(165 \pm 148 \mathrm{nmol} \cdot \mathrm{min}^{-1} ; \mathrm{ES}=0.09 ; P=0.751\right)$. However, ONR in NR was 59.7\% higher in PM-Pre compared to AM-Pre $(P=0.046$; $E S=0.62$ ). There was no correlation between morning training session duration and ONR at the AM-Post, PM-Pre or PM-Post time points ( $r \leq 0.30, P \geq 0.329)$ or between afternoon session length and the PM-Post ONR $(r=0.19, P=0.545)$.

\section{Discussion}

The novel findings from this study in elite swimmers were: 1) ONR did not differ from that observed in non-swimmers; 2) ONR was not attenuated following a single or multiple pool sessions, but was enhanced in the afternoon compared with the morning, on the same day; and 3) ONR was not correlated with the duration of the pool-based training sessions. Collectively, these observations suggest that exposure to chlorinated pool water does not interfere with ONR in elite swimmers.

Several previous studies have reported a detrimental effect of antibacterial chlorohexidine mouthwash on ONR capacity (Kapil et al. 2013, 2018; Bondonno et al. 2015; McDonagh et al. 2015; Sundqvist et al. 2016; Woessner et al. 2016; Ashworth et al. 2019; Bescos et al. 2020). However, despite the established antimicrobial properties of chlorine, and contrary to our hypothesis, there was no difference between the abilities of swimmers and non-swimmers to form $\mathrm{NO}_{2}^{-}$in the oral cavity when administered a NR mouth rinse. Furthermore, there was no impairment in ONR 
following morning or afternoon in-water training sessions on the same day, nor was the session duration correlated with the post session ONR in the current study. Our findings suggest that frequent exposure to chlorinated water through regular poolbased training does not influence ONR in elite swimmers compared to non-swimmers. Therefore, the lack of an ergogenic effect of $\mathrm{NO}_{3}{ }^{-}$supplementation previously reported in trained swimmers (Lowings et al. 2017; Jonvik et al. 2018; Esen et al. 2019) is unlikely to be a function of impaired ONR. However, additional research is required to elucidate whether the oral microbiome of frequent swimmers develops a tolerance to chlorine-sterilised pool water and whether infrequent pool-users would experience acute reductions in ONR upon exposure to chlorinated pool water. We also cannot exclude the possibility that maintaining the pool chlorine concentration closer to the upper limit of the recommended guidelines of $1-3 \mathrm{mg} / \mathrm{L}$ (WHO 2006) could impair ONR in swimmers. We did not directly assess the aerobic fitness status of our nonswimming controls and acknowledge this as a study limitation since ONR has been shown to correlate positively with aerobic fitness (Thomas et al. 2019).

Although ONR was not impaired after, compared to before, pool-based training, ONR was higher prior to the afternoon training session compared to the morning. It is well documented that the oral microflora catalyse the reduction of $\mathrm{NO}_{3}{ }^{-}$to $\mathrm{NO}_{2}{ }^{-}$, and several important $\mathrm{NO}_{3}{ }^{-}$reducing bacterial genera have been identified including: Veillonella, Neisseria, Prevotella, Actinomyces, Rothia, Granulicatella, Staphylococcus, Propionibacterium and Haemophilus (Doel et al. 2005; Hyde et al. 2014). Indeed, the abundance of these genera of oral $\mathrm{NO}_{3}{ }^{-}$reducers has been shown to impact the magnitude of salivary and plasma $\left[\mathrm{NO}_{2}{ }^{-}\right]$following $\mathrm{NO}_{3}{ }^{-}$ingestion (Burleigh et al. 2018; Vanhatalo et al. 2018). It appears that the oral microbiome exhibits circadian oscillation patterns, with proliferation of Prevotella in the morning and Neisseria and Rothia genera in the afternoon (Takayasu et al. 2017). Since Vanhatalo et al. (2018) indicated that high abundances of Rothia and Neisseria and low abundances of Prevotella were conducive to greater increases in $\mathrm{NO}_{2}{ }^{-}$synthesis following dietary $\mathrm{NO}_{3}{ }^{-}$supplementation, this might have accounted for the greater ONR observed in the current study in the afternoon compared to the morning.

In conclusion, our findings indicate that exposure to chlorinated pool water does not interfere with the capacity of elite swimmers to reduce $\mathrm{NO}_{3}{ }^{-}$in the oral cavity. 


\section{Conflict of interest}

The authors declare no conflict of interest.

237

\section{Reference list}

Ashworth, A., Cutler, C., Farnham, G., Liddle, L., Burleigh, M., Rodiles, A., Sillitti, C., Kiernan, M., Moore, M., Hickson, M., Easton, C., and Bescos, R. 2019. Dietary intake of inorganic nitrate in vegetarians and omnivores and its impact on blood pressure, resting metabolic rate and the oral microbiome. Free Radic. Biol. Med. 138: 63-72. doi:10.1016/j.freeradbiomed.2019.05.010.

Bescos, R., Ashworth, A., Cutler, C., Brookes, Z.L., Belfield, L., Rodiles, A., CasasAgustench, P., Farnham, G., Liddle, L., Burleigh, M., White, D., Easton, C., and Hickson, M. 2020. Effects of Chlorhexidine mouthwash on the oral microbiome. Sci. Rep. 10(1): 5254. doi:10.1038/s41598-020-61912-4.

Bondonno, C.P., Liu, A.H., Croft, K.D., Considine, M.J., Puddey, I.B., Woodman, R.J., and Hodgson, J.M. 2015. Antibacterial mouthwash blunts oral nitrate reduction and increases blood pressure in treated hypertensive men and women. Am. J. Hypertens. 28(5): 572-575. doi:10.1093/ajh/hpu192.

Burleigh, M.C., Liddle, L., Monaghan, C., Muggeridge, D.J., Sculthorpe, N., Butcher, J.P., Henriquez, F.L., Allen, J.D., and Easton, C. 2018. Salivary nitrite production is elevated in individuals with a higher abundance of oral nitrate-reducing bacteria. Free Radic. Biol. Med. 120: 80-88. doi:10.1016/j.freeradbiomed.2018.03.023.

Doel, J.J., Benjamin, N., Hector, M.P., Rogers, M., and Allaker, R.P. 2005. Evaluation of bacterial nitrate reduction in the human oral cavity. Eur. J. Oral Sci. 113(1): 14- 

19. doi:10.1111/j.1600-0722.2004.00184.x.

259

260

261

262

263

264

265

266

267

268

Esen, O., Nicholas, C., Morris, M., and Bailey, S.J. 2019. No effect of beetroot juice supplementation on $100-\mathrm{m}$ and $200-\mathrm{m}$ swimming performance in moderately trained swimmers. Int. J. Sports Physiol. Perform. 14(6): 706-710. Human Kinetics Publishers Inc. doi:10.1123/ijspp.2018-0654.

Govoni, M., Jansson, E.Å., Weitzberg, E., and Lundberg, J.O. 2008. The increase in plasma nitrite after a dietary nitrate load is markedly attenuated by an antibacterial mouthwash. Nitric Oxide - Biol. Chem. 19(4): 333-337. doi:10.1016/j.niox.2008.08.003.

Hyde, E.R., Andrade, F., Vaksman, Z., Parthasarathy, K., Jiang, H., Parthasarathy, D.K., Torregrossa, A.C., Tribble, G., Kaplan, H.B., Petrosino, J.F., and Bryan, N.S. 2014. Metagenomic analysis of nitrate-reducing bacteria in the oral cavity: Implications for nitric oxide homeostasis. PLoS One. 9(3): 88645. doi:10.1371/journal.pone.0088645.

Jones, A.M., Thompson, C., Wylie, L.J., and Vanhatalo, A. 2018. Dietary Nitrate and Physical Performance. Annu. Rev. Nutr. 38: 303-328. doi:10.1146/annurev-nutr$082117-051622$.

Jonvik, K.L., Van Dijk, J.W., Senden, J.M.G., Van Loon, L.J.C., and Verdijk, L.B. 2018. The effect of beetroot juice supplementation on dynamic apnea and intermittent sprint performance in elite female water polo players. Int. J. Sport Nutr. Exerc. Metab. 28(5): 468-473. doi:10.1123/ijsnem.2017-0293.

Kapil, V., Haydar, S.M.A., Pearl, V., Lundberg, J.O., Weitzberg, E., and Ahluwalia, A. 2013. Physiological role for nitrate-reducing oral bacteria in blood pressure control. Free Radic. Biol. Med. 55: 93-100. 

doi:10.1016/j.freeradbiomed.2012.11.013.

283

284

Kapil, V., Rathod, K.S., Khambata, R.S., Bahra, M., Velmurugan, S., Purba, A., S. Watson, D., Barnes, M.R., Wade, W.G., and Ahluwalia, A. 2018. Sex differences in the nitrate-nitrite-NO - pathway: Role of oral nitrate-reducing bacteria. Free Radic. Biol. Med. 126: 113-121. doi:10.1016/j.freeradbiomed.2018.07.010.

Lowings, S., Shannon, O.M., Deighton, K., Matu, J., and Barlow, M.J. 2017. Effect of dietary nitrate supplementation on swimming performance in trained swimmers. Int. J. Sport Nutr. Exerc. Metab. 27(4): 377-384. doi:10.1123/ijsnem.2016-0251.

McDonagh, S.T.J., Wylie, L.J., Winyard, P.G., Vanhatalo, A., and Jones, A.M. 2015. The effects of chronic nitrate supplementation and the use of strong and weak antibacterial agents on plasma nitrite concentration and exercise blood pressure. Int. J. Sports Med. 36(14): 1177-1185. doi:10.1055/s-0035-1554700.

Senkus, K.E., and Crowe-White, K.M. 2019. Influence of mouth rinse use on the enterosalivary pathway and blood pressure regulation: A systematic review. Crit Rev Food Sci Nutr. 23: 1-13. doi:10.1080/10408398.2019.1665495.

Sund-Levander, M., Forsberg, C., and Wahren, L.K. 2002. Normal oral, rectal, tympanic and axillary body temperature in adult men and women: A systematic literature review. Scand. J. Caring Sci. 16(2): 122-128. doi:10.1046/j.14716712.2002.00069.x.

Sundqvist, M.L., Lundberg, J.O., and Weitzberg, E. 2016. Effects of antiseptic mouthwash on resting metabolic rate: A randomized, double-blind, crossover study. Nitric Oxide - Biol. Chem. 61: 38-44. doi:10.1016/j.niox.2016.10.003.

Takayasu, L., Suda, W., Takanashi, K., lioka, E., Kurokawa, R., Shindo, C., Hattori, 
Y., Yamashita, N., Nishijima, S., Oshima, K., and Hattori, M. 2017. Circadian oscillations of microbial and functional composition in the human salivary microbiome. DNA Res. 24(3): 261-270. doi:10.1093/dnares/dsx001.

Thomas, B., Smallwood, S., Cutler, C., and Bescos, R. 2019. The oral nitratereducing capacity correlates with peak power output and peak oxygen uptake in healthy humans. Nitric Oxide - Biol. Chem. 87: 43-51. doi:10.1016/j.niox.2019.03.001.

Tribble, G.D., Angelov, N., Weltman, R., Wang, B.Y., Eswaran, S. V., Gay, I.C., Parthasarathy, K., Dao, D.H. V., Richardson, K.N., Ismail, N.M., Sharina, I.G., Hyde, E.R., Ajami, N.J., Petrosino, J.F., and Bryan, N.S. 2019. Frequency of tongue cleaning impacts the human tongue microbiome composition and enterosalivary circulation of nitrate. Front. Cell. Infect. Microbiol. 9: 39. doi:10.3389/fcimb.2019.00039.

Vanhatalo, A., Blackwell, J.R., L'Heureux, J.E., Williams, D.W., Smith, A., van der Giezen, M., Winyard, P.G., Kelly, J., and Jones, A.M. 2018. Nitrate-responsive oral microbiome modulates nitric oxide homeostasis and blood pressure in humans. Free Radic. Biol. Med. 124: 21-30. doi:10.1016/j.freeradbiomed.2018.05.078.

WHO. 2006. Guidelines for safe recreational water. Volume 2, Swimming pools and similar environments. 1-146. ISBN 9241546808.

Woessner, M., Smoliga, J.M., Tarzia, B., Stabler, T., Van Bruggen, M., and Allen, J.D. 2016. A stepwise reduction in plasma and salivary nitrite with increasing strengths of mouthwash following a dietary nitrate load. Nitric Oxide - Biol. Chem. 54: 1-7. doi:10.1016/j.niox.2016.01.002. 


\section{$329 \quad$ Figure legend}

330 Figure 1. Morning oral nitrite production in non-swimmers and swimmers. Data are 331 presented as group median (solid line) and individual responses (circles). No 332 differences were observed between groups $(P=1.000)$. Oral nitrite production in elite 333 swimmers pre and post morning (AM-Pre and AM-Post) and afternoon (PM-Pre and 334 PM-Post) pool-based training sessions in nitrate-rich (NR, squares) and nitrate335 depleted (PL, circles) conditions. Data are presented as group mean \pm SEM. * 336 indicates oral nitrite production was higher in the NR condition compared to all time 337 points in the PL condition $(P \leq 0.002)$. \# indicates oral nitrite production was higher 338 PM-Pre compared to AM-Pre in the NR condition $(P=0.046)$. 

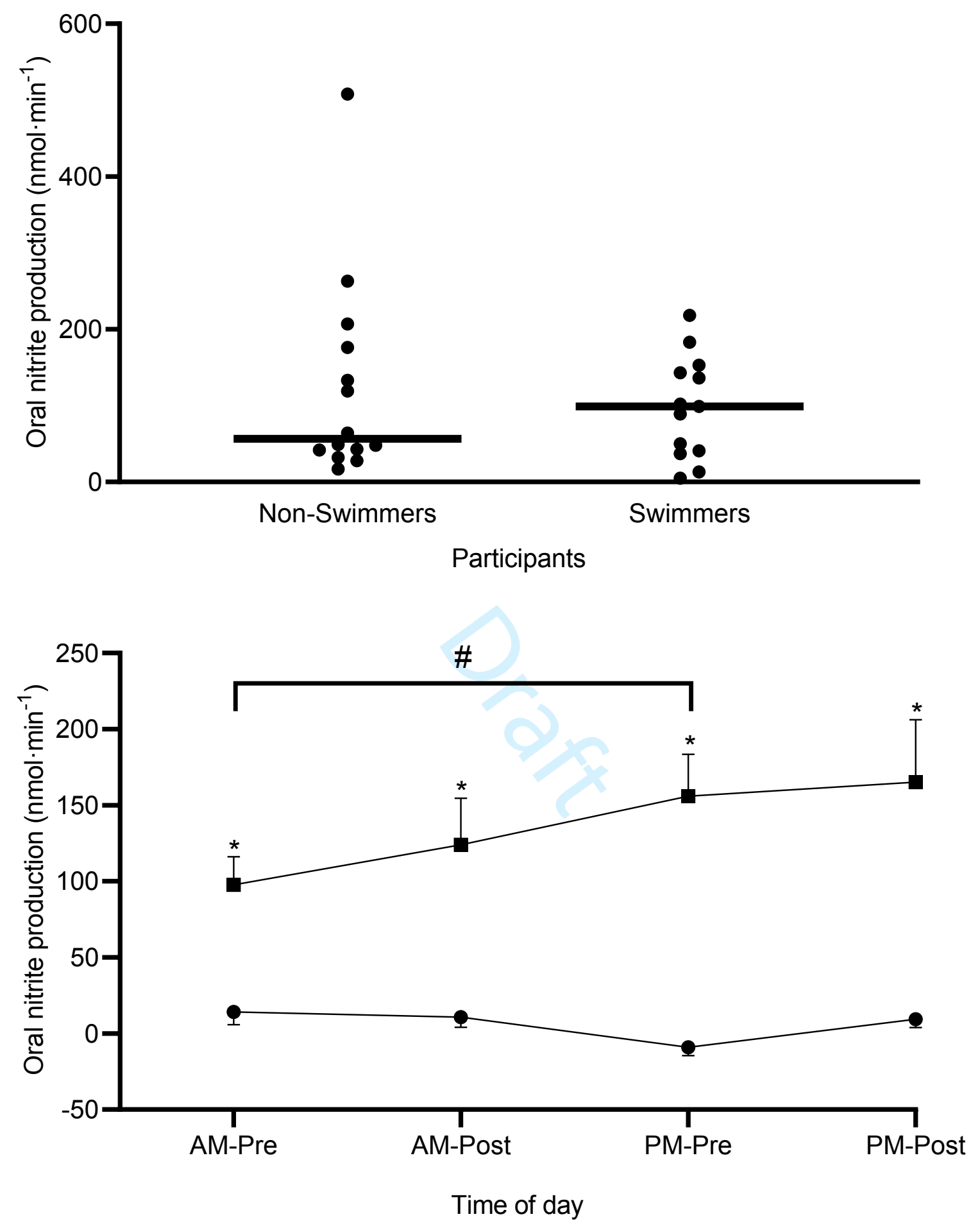